\title{
BASIC ENERGY-SAVING PRINCIPLES AT THE ENTERPRISES OF PUBLIC CATERING
}

\author{
Pulatov Abror ${ }^{1}$ \\ ${ }^{1}$ Tashkent State technical university, Department of Electromechanics and Electrotechnologies, Universitetskaya - 2, \\ Tashkent, 100095, Uzbekistan
}

\begin{abstract}
The main principles of energy saving at public catering enterprises are considered in this article. The main criterion for this analysis is the consumption of electric energy by catering enterprises, which averages $80-90 \%$ of all energy consumption. Most of this equipment is non-adaptive and nonautomated, its installed capacity is often several times more than the actual required capacity, and the average load is on average $30-60 \%$. In this regard, the research and wide introduction of energy-saving technologies and devices in catering enterprises is an urgent task. The article also analyzes the possibilities of reducing the specific consumption of electricity and the functioning of devices at catering enterprises.
\end{abstract}

\section{Introduction}

In modern conditions, when the operation of enterprises directly depends on their financial stability, profitability and contributing to the relatively low unit cost of production, energy saving is an important and urgent problem. Certainly, this problem is entirely related to various public catering enterprises (restaurants, cafes, bistros, fast food...). Therefore, in the conditions of constantly increasing competition, the rationale use of energy resources and electric energy is one of the most important tasks along with marketing and financial ploys, advertising (promotions), complying development, research and widespread implementation of energy-saving technologies and devices is an urgent task [1-5].

As you know, modern public catering enterprises have a high energy capacity, and the consumption of electric energy is on average $80-90 \%$ of all types of energy consumption. The main part of electrical installations does not have deep regulation and rigid stabilization of output parameters. Out of the total number of electric receivers (refrigerators, hoods, air conditioners, meat grinders, food processors, lighting, etc.), only a small part of objects (induction stoves, electric ovens, coffee machines...) has a complex and finely controlled technological process.

The vast majority of these mechanisms are nonadaptive and non-automated, their installed capacity is often several times more than the actual required capacity, and the average load is on average $30-60 \%$.

Taking into account that the total expenses for the maintenance of institutions, the cost of electricity consumption is significant and, according to independent experts, sometimes reaches 30 percent or more. Let's consider what the consumed electricity is spent on: cooking (20-30\%), space heating (15-20\%), water heating (5-10\%), outdoor and indoor lighting (8$12 \%$ ), air conditioning (up to $15-20 \%$ per season) and from $30-40 \%$ for other needs. Places of public catering working day and night (fast food, pizzerias, etc.), the technological mode of which can not be clear in advance and associated with the population demand and solvency, when cooking due to a higher specific energy capacity (electric pans, stoves, grills, etc.), spend about $10-15 \%$ more electricity due to uneven loading of electric receivers.

It should be noted that electric energy consumption depends not only on the "electromagneti", but on the automation degree as well. Electric power consumption is directly related to the regulation degree of necessary power, proper selection of equipment, capacity, quantity, performance and correct location.

Let's consider the possibilities of reducing the specific electricity consumption in public catering places [6-8].

\section{Lighting}

Lighting is divided into internal and external. Indoor lighting-hall, kitchen, utility rooms, cabins, etc. Here energy saving is primarily associated with the correct choice of energy-efficient lighting devices, optimizing their number, power and location. Artful variation in light and shade and color of walls and ceilings is not unimportant. It is known that the correct choice of window openings, drapery and color selecton of painting ( a designer's task) allows us to save up to 30$40 \%$ on lighting. External lighting-lighting of adjacent territories and advertising, where energy saving is primarily associated with the correct choice of energyefficient lighting devices, the ability to select correctly their number, power, height, and automation for illumination level. 
Note that a failure in the automation often leads to the inclusion of lighting in a larger volume than is actually required. This can lead to additional power consumption of $5-8 \%$ [9-13].

\section{Refrigeration equipment}

In each institution, depending on its specifics, refrigeration equipment is installed. Analysis of the refrigeration equipment operation shows that energy consumption is greatly influenced by the correct selection of the volume of the refrigerator, its location (away or nearby the heating zones), correct operation, timely detection and correction of problems. In general, it is desirable to place the refrigeration equipment in a separate room or at least screen it. It should be noted that the correct selection of the refrigerator volume is one of the main criteria and parameters of refrigeration equipment, both low loading of the refrigerator and its restart, as well as rational placement of products inside the volume primarily affect the safety of products and the stable operation of the refrigerator (freezer), and also significantly affect the duration of the equipment, as well as the cost of its repair [14].

\section{Ventilation system}

The ventilation system is also an important component in the overall energy consumption of each catering company. Ventilation of premises naturally occurs, but this aspect is seasonal and can be considered in rare cases - when weather conditions allow and the institution is just starting to work or closes. The inflow of fresh air and the outflow of heated air guarantees uninterrupted operation of both the kitchen and the hall itself. Analysis of the operation and energy consumption of the ventilation system shows that the correct selection of supply and exhaust ventilation points, the type (centrifugal or axial) and the number of fans significantly affect the overall energy consumption of the ventilation system (air conditioning). Another important aspect is proper operation and automation (local management) of the system units. It is no secret that untimely disconnection or use of single-speed fans in exhaust equipment leads to an additional (inefficient) increase in electrical energy consumption up to $30 \%$ of the necessary (useful) [15-17].

\section{Electric heating equipment}

Electric heating equipment provides the technological process of cooking-electric stoves, ovens, induction installations, electric cookers, grills, etc., their operating mode is almost impossible to predict or program, the greatest increase in electric energy consumption is associated with a low coefficient of loading and use of equipment, often this equipment is in standby mode (except for planned major events, such as corporate parties, birthdays, weddings, etc.). Therefore, the correct selection of the equipment itself, the heating principle (induction installations have higher energy indicators), the rational use of volume (ovens, grills, stoves), their technical characteristics, the correct location significantly affects the overall energy consumption of heating devices. Another important aspect is the correct operation and the presence of smooth regulation of the parameters of the electrical installation instead of a step-by-step, the presence of maintaining the set temperature. If the equipment is not chosen rationally, this in turn will lead to excessive energy consumption [18].

\section{Losses in the electrical network}

A strong influence on losses in the supply networks and, accordingly, in the overall balance of energy consumption has an asymmetry of the load, the operating mode of the equipment "stand-by" and the correct choice of the cross-section of the current pipelines. With uneven distribution of load capacity in phases, and often no one is engaged in this and as a rule, the load is mainly single-phase, there is a significant asymmetry of currents (up to $70 \%$ ) and voltages (up to $30 \%$ ) in phases, which has negative consequences on the elements of the supply network. This primarily leads to frequent power outages and premature failure of electrical receivers or network elements. For example, an increase in the voltage of fan motors leads to an increase in the consumption (up to $30 \%$ on average) of reactive energy, and, consequently, to a significant increase in the associated losses. At the same time, it is unacceptable to discount the growth of losses in transformers due to asymmetry. Let's consider the indicators of electricity consumption on the example of a round-the-day fast food in the city of Tashkent.

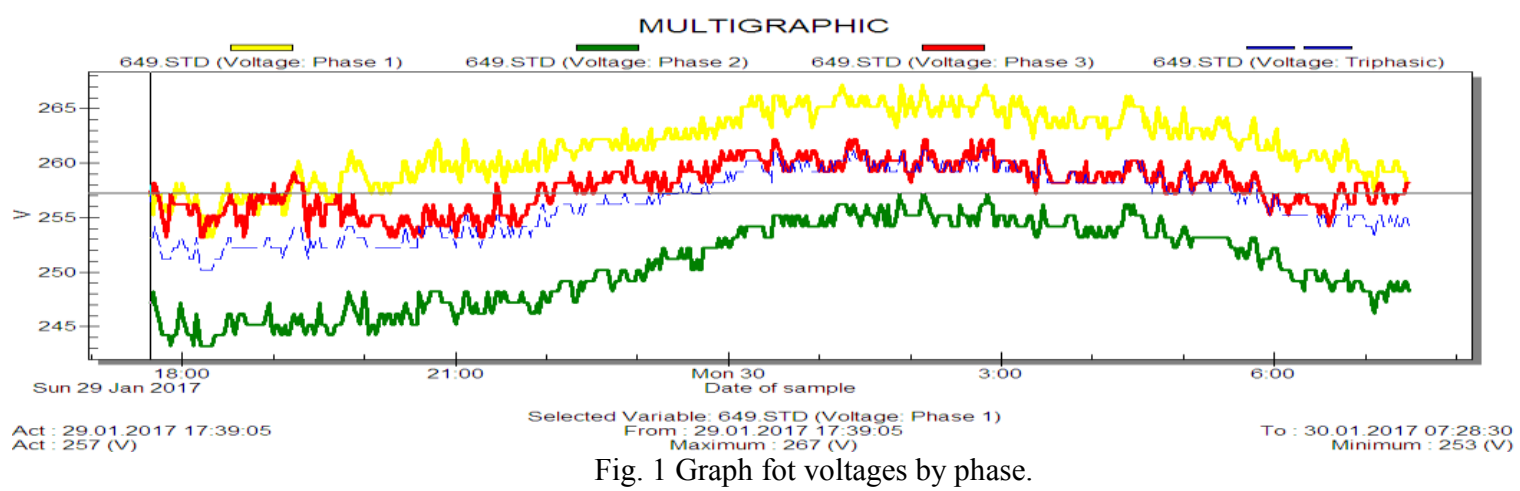


The value of the voltage in the power supply network at the time of connecting the load of the consumer, was recorded in the range of 241 volts (in phase "B"), and up to 267 volts (in phase "A"). During the evening and morning "load maximums", there is an increase in the non-symmetry of the voltage (up to 26 volts), The increase in the voltage at night, especially in phase" $\mathrm{A}$ ", was in excess of the nominal value, up to $21.36 \%$.

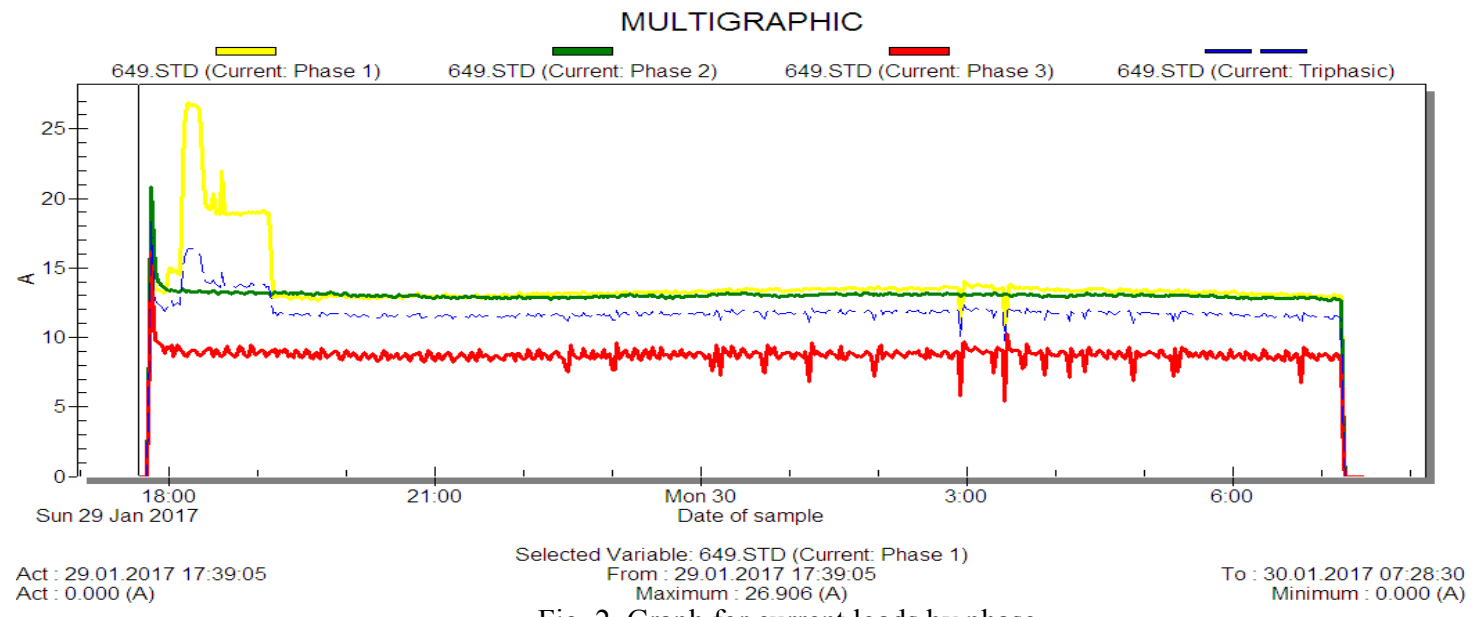

Fig. 2. Graph for current loads by phase.

At the time of connecting consumers to the network, the starting currents are recorded. There is a significant current asymmetry, which is explained by the differently distributed load in phases. On the "night" measurement chart, during the time period from
1800 to 1920 , an unjustified increase in the load current in phase "A" was recorded, associated with the calibration of all electrical receivers in the network during the change.

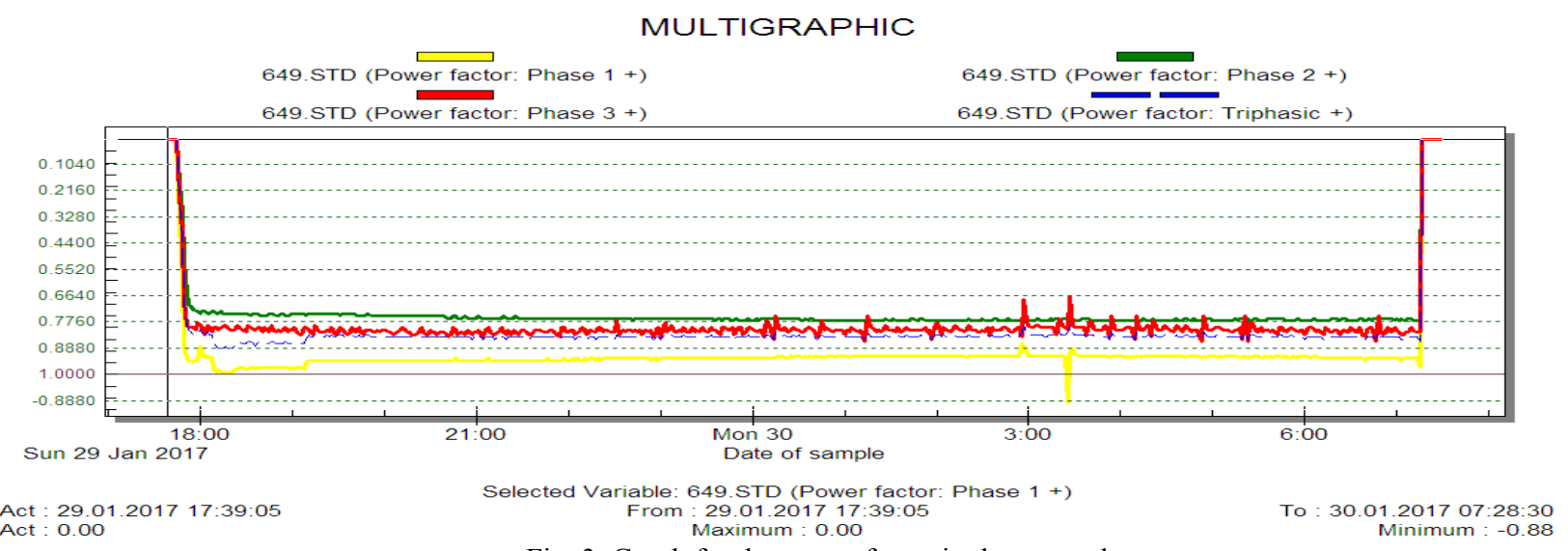

Fig. 3. Graph for the power factor in the network.

A relatively low value of the power factor in the network was recorded, for phases " $\mathrm{B}$ "and" C", from 0.67 to 0.86 (especially for phase" $\mathrm{B} " 0.67$ ). This means that about $65-75 \%$ of the current (power) is reactive and leads to a significant increase in power losses [19-21].

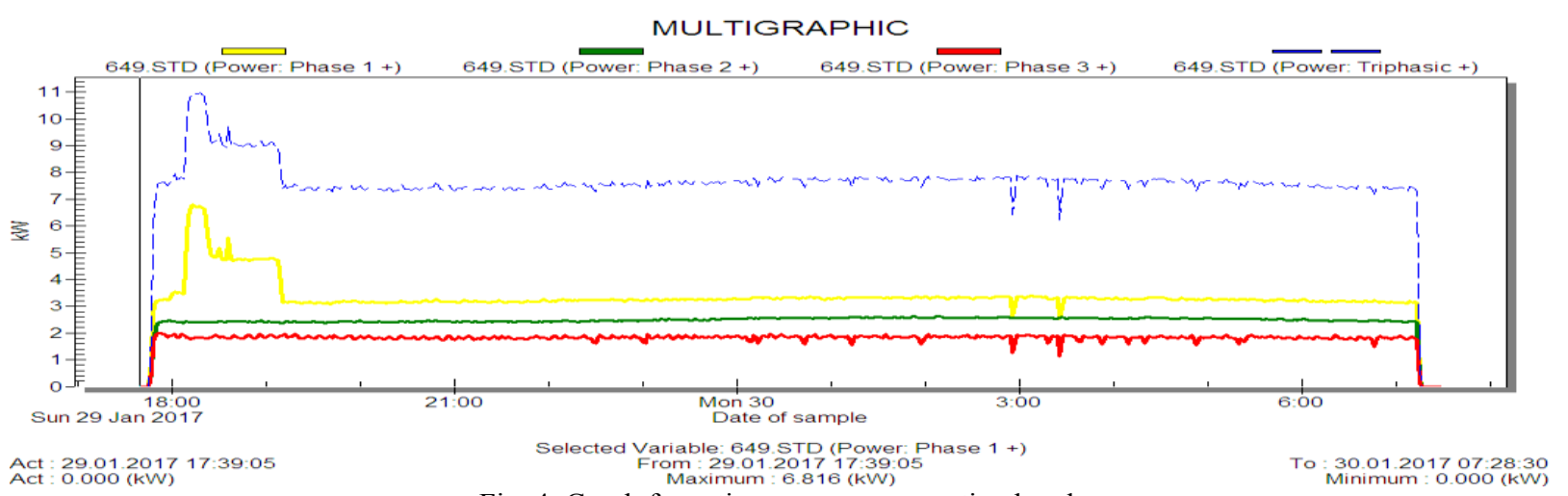

Fig. 4. Graph for active power consumption by phase. 
The total active power consumption ranged from 7 $\mathrm{kW}$ to $11 \mathrm{~kW}$. The graph shows a significant asymmetry in the distribution of active load by phase. The total reactive power consumption ranged from 3.5 $\mathrm{kVAr}$ to $5 \mathrm{kVAr}$. When connecting a current load, a multiple increase in power consumption is recorded due to the connection of an induction load (plate). There is an asymmetry in the distribution of the reactive load in phases.

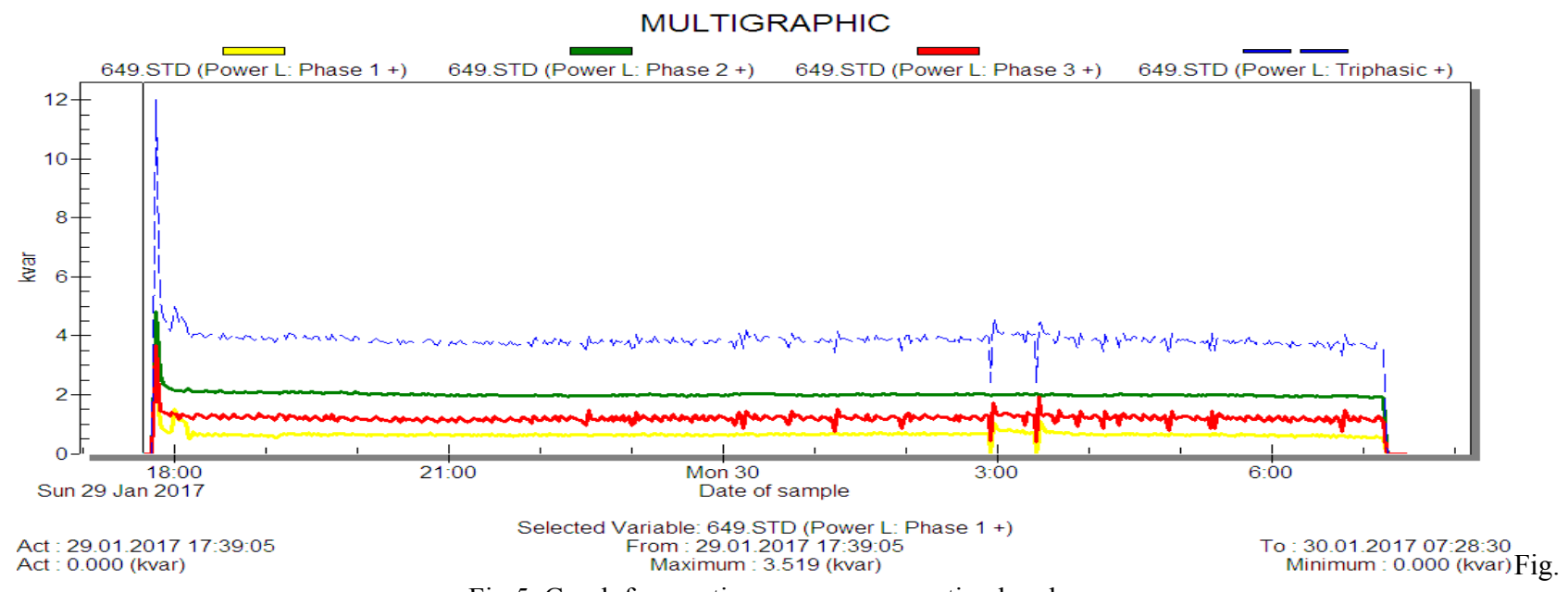

Fig.5. Graph for reactive power consumption by phase.

Therefore, a thorough study (energy audit) of energy consumption, analysis of operating modes of all types of electrical equipment and timely adjustment of operating modes, as well as their correct loading and operation, will significantly reduce electricity costs in general, and savings from electricity consumption can rise up to $30-40 \%$ compared to the original numbers [22-28].

It should be noted that the latest trends in the economic development of the sphere have formed new realities in the strategy of public catering enterprises, and the issues considered during the corona virus pandemic are particularly relevant. Tough legislative initiatives, rising food prices, rising electricity prices, labor market conditions and the tax system have required new resource-saving and cost-effective solutions for cost optimization from restaurateurs. The issue of increasing profitability in the service sector is not only a question of effective sales management, promotion and expansion of the business, but first of all, the introduction of effective methods of work, effective management and well-established accounting. Moreover, increasing the energy efficiency of an institution contributes not only to reasonable savings, but is also a fundamental basis for effective enterprise management.

\section{References}

1. Kolesnikov A.I., Fedorov M.N. Energy saving in industrial and utilities. Infra-M, $2010-128 \mathrm{p}$.

2. Kavetskiy G.D., Kasianenko V.P. Processes and devices of food technology: Textbook for universities 3rd edition - 2008.

3. Kavetsky G.D., Vorobieva A.V. Technological processes and production (Food industry) $\mathrm{M}$.:Kolos, $2006-367$ p.
4. Khashimov A.A., Imamnazarov A.T., Pulatov A.A. Thermal operating modes of induction crucible furnaces. Tashkent:2012 - $125 \mathrm{p}$.

5. Khashimov A.A., Imomnazarov A.T., Pulatov A.O. Mathematical model of metal melting processes in crucible furnaces. International Simposium on Helting by Electrotermic Sourses, Padua (Italy), June 22-25, 2004.

6. Toshov, Zh.B. Ways towards optimization of washout components of rock cutting tools Information about author // Gornyi Zhurnal. Volume 2016, Issue 2, 1 January 2016, Pages 21-24.

7. Burievich, T.J. The questions of the dynamics of drilling bit on the surface of well bottom// Arch. Min. Sci. -Poland. - Vol. 61 (2016). - №2. - P. 279-287. DOI 10.1515/amsc-2016-0020.

8. Toshniyozov, L.G., Toshov, J.B. Theoretical and experimental research into process of packing in drilling// Mining Informational and Analytical Bulletin Volume 2019, Issue 11, 2019, Pages 139-151. DOI: 10.25018/0236-1493-2019-11-0-139-151.

9. Avezova N.R., Toshov J.B., Dalmuradova N.N., Farmonova A.A., Mardonova M.Sh.Renewable Energy: Scenario and Model of Development // ISSN 0003-701X, Applied Solar Energy, 2019, Vol. 55, No. 6, pp. 438-445. DOI: 10.3103/S0003701X19060021

10. Rakhmonov, I.U., Niyozov, N.N. (2019) Optimization setting of steel-smelting industry in the issue of alloy steels E3S Web Conf 139 doi:10.1051/e3sconf /201913901077

11. Mannanov U., Toshov J., Toshniyozov L. Perspective Solutions for the Design of Drilling Tools / E3S Web of Conferences 105, 03027 (2019) IVth International Innovative Mining Symposium, https://doi.org/10.1051/e3sconf/201910503027

12. Toshov J., Saitov E. Portable autonomous solar power plant for individual use / E3S Web Conf., Volume 139, 01087, 2019, Rudenko International Conference "Methodological problems in reliability 
study of large energy systems" (RSES 2019), https://doi.org/10.1051/e3sconf/201913901087

13. Azamatovich, A.N., Amrillo, M.B, Burievich, T.J., Umarxanoxich, J.R., Shavkatovich, Z.A. A complex of methods for analyzing the working fluid of a hydrostatic power plant for hydraulic mining machines / International Journal of Advanced Science and Technology. Volume 29, Issue 5 Special Issue, 28 March 2020, Pages 852-855

14. Rakhmonov, I. U., Tovbaev, A.N., Nematov, L.A., Alibekova,T.Sh. (2020) Development of forecasted values of specific norms for the issues of produced products in industrial enterprises Journal of Physics: Conference Series $\mathbf{1 5 1 5}$ doi:10.1088/17426596/1515/2/022050

15. Rakhmonov, I.U., Nematov, L.A., Niyozov, N.N, Reymov, K.M., Yuldoshev, T.M. (2020) Power consumption management from the positions of the general system theory Journal of Physics: Conference Series 1515 doi:10.1088/1742-6596/1515/2/022054

16. Rakhmonov, I. U., Reymov, K.M., Dustova, S.H. (2020) Improvements in industrial energy rationing methods Journal of IOP: Conference Series. MIP: $\begin{array}{llll}\text { Engineering-2020. } & 862 \quad \text { (2020) } & 062070\end{array}$ doi:10.1088/1757-899X/862/2/062070

17. Rakhmonov, I.U., Berdishev, A.A., Niyozov, N.N., Muratov, A., Khaliknazarov U. (2020) Development of a scheme for generating the predicted value of specific electricity consumption Journal of IOP: Conference Series. MIP: Engineering-2020. 883 (2020) 012103 doi:10.1088/1757-899X/883/1/012103

18. Rakhmonov, I.U., Berdishev, A.A., Khusanov, B.M., Khaliknazarov, U., Utegenov, U. (2020) General characteristics of networks and features of electricity consumers in rural areas Journal of IOP: Conference Series. MIP: Engineering-2020. 883 (2020) 012104 doi:10.1088/1757-899X/883/1/012104

19. Hoshimov, F.A., Bakhadirov, I.I., Erejepov, M., Djumamuratov, B. (2019) Development of method for normalizing electricity consumption E3S Web Conf 139 doi:10.1051/e3sconf/201913901074

20. Karimov R.Ch., Bobojanov M.K., Rasulov A.N., Usmanov E.G. E3S Web of Conferences, 139, 01039, (2019), doi.org/10.1051/e3sconf/201913901039;

21. Karimov R.Ch., Shamsiyeva N. and others. IOP Conf. Series: Materials Science and Engineering, 883(1), 012120, (2020). doi:10.1088/1757$899 X / 883 / 1 / 012120$

22. G.R.Rafikova,

M.R.Ruzinazarov, S.K.Makhmutkhonov. E3S Web of Conferences, 139, 01075,

(2019),

https://doi.org/10.1051/e3sconf/201913901075

23. Allayev, K.R., Fedorenko, G.M.,Postnikov, V.I.,Ostapchuk, L.B. Asynchronous generators as power system's natural dampers. 43rd International Conference on Large High Voltage Electric Systems 2010, CIGRE 20102010, 9p43rd International Conference on Large High Voltage Electric Systems 2010, CIGRE 2010; Paris; France; 22 August 2010.

24.Fazylov, Kh.F.,Allaev, K.R. Analysis of the operation of an electrical system during simultaneous operation of synchronous and asynchronous generators. Power engineering New York Volume 18, Issue 3, 1980, Pages 81-88.

25.Fazylov, Kh.F.,Allaev, K.R. Asynchronous turbogenerators with stator excitation and the prospects for their utilization. Power engineering New York Volume 23, Issue 2, 1985, Pages 7-13.

26.Fazylov, Kh.F.,Allaev, K.R. Calculation and experimental analysis of conditions of electrical power systems containing induction generators Power Engineering New York Volume 27, Issue 6, 1989, Pages 27-34.

27.Allaev K., Makhmudov T. Research of small oscillations of electrical power systems using the technology of embedding systems. Electrical Engineering, 2020; Issue 1: 309-319.DOI 10.1007/s00202-019-00876-9

28.Allaev K., Makhmudov T. Prospects of diversification and ensuring energy safety of Uzbekistan. E3S Web Conf., Volume 139, 2019, Rudenko International Conference "Methodological problems in reliability study of large energy systems" (RSES2019).https://doi.org/10.1051/e3sconf/20191390 1002 